\title{
DIAGNÓSTICO DAS \\ DIFICULDADES DO ENSINO \\ DE HISTÓRIA NO QUE TANGE \\ À IDENTIDADE QUILOMBOLA \\ EM PRESIDENTE KENNEDY-ES
}

- Vânia dos Santos da Silva

SSebastião Pimentel Franco

\section{INTRODUÇÃO}

Esta pesquisa tem por tema de estudo "Diagnóstico do ensino nas escolas quilombolas de Presidente Kennedy - ES”, as quais estão localizadas no município de Presidente Kennedy, no litoral do Espírito Santo. São comunidades rurais a dois quilômetros da Rodovia ES-462, no sentido Presidente Kennedy-Marataízes-Rio de Janeiro. Constituída de $97 \%$ de população negra, a comunidade foi reconhecida como quilombola pela Fundação Palmares em 23 de agosto de 2005.

Quilombolas são comunidades tradicionais que, ao fugirem dos senhores de escravos, procuravam a liberdade em áreas distantes e de difícil acesso, para se protegerem de possíveis perigos, formando, desse modo, os espaços de convivência coletiva. Com o tempo dessas fugas, foram formando novas comunidades mesmo após a extinção da escravatura.

De aspecto complementar, Arruti (1997, p. 22) explica a complexidade e a riqueza contidas no termo "remanescentes":

\footnotetext{
Ao serem identificados como 'remanescentes', aquelas comunidades em lugar de representarem os que estão presos às relações arcaicas de produção e reprodução social, aos misticismos e aos atavismos próprios do mundo rural [...] passam a ser reconhecidas como símbolo de uma identidade, de uma cultura e, sobretudo, de um modelo de luta e militância negra.
}

O trabalho busca apresentar como funcionam as escolas das comunidades quilombolas de Presidente Kennedy no Espírito Santo, verificando se o processo educacional delas contribui para que os escolares se reconheçam como quilombolas.

Para que os moradores dessas comunidades se reconheçam quilombolas, é preciso que eles valorizem e preservem a sua memória, tal qual nos preceitua Le Goff (1994, p. 423), ao afirmar que a compreensão do conceito de memória é crucial no sentido de que, 
[...] como propriedade de conservar certas informações, a memória remete-nos em primeiro lugar a um conjunto de funções psíquicas, graças às quais o homem pode atualizar impressões ou informações passadas, ou que ele representa como passadas.

Por intermédio da Constituição Federal de 1988, também conhecida como Constituição Cidadã, no Brasil se estabeleceu que quilombolas fossem reconhecidos como cidadãos, garantindo-lhes direitos sociais, como acesso à saúde, educação, entre outros. No que concerne à educação, estabeleceu-se que deveriam existir escolas próprias em todas as comunidades quilombolas.

Desse modo, pretendemos, com nossa pesquisa, vislumbrar como vivem as comunidades quilombolas de Presidente Kennedy, buscando verificar como esses remanescentes se identificam como quilombolas e de que forma a escola local tem contribuído para o resgate dessa identificação e, consequentemente, da luta em busca da cidadania plena.

Assim, o educando deve ter acesso a uma educação que considere sua cultura e atenda aos requisitos de qualidade educacionais, contemplando ainda a diversidade regional em que cada comunidade está inserida, além da realidade social, histórica, política, econômica e cultural desse povo.

Nessa perspectiva, a pesquisa pretende obter respostas ao seguinte problema: Quais experiências são evidenciadas pelos alunos das escolas quilombolas para que eles tenham noção de pertencimento a uma comunidade remanescente? Como objetivo geral, pretende-se diagnosticar o ensino disponibilizado aos alunos nas comunidades quilombolas de Presidente Kennedy-ES, verificando se ele possibilita aos escolares ter a noção de pertencimento como remanescentes de comunidade quilombola. A necessidade de discutir esse tema justifica-se pela urgência de pôr em pauta o tema relativo à preservação e valorização da cultura quilombola como parte integrante do currículo escolar, à importância de trabalhar a história local para a autoafirmação e preservação da cultura quilombola. A metodologia empregada na pesquisa é de natureza qualitativa, por permitir, conforme afirmam Ludke e André (1986, p. 12), uma riqueza de "[...] descrições de pessoas, situações, acontecimentos [...]", em que se verifica in loco estudar os fenômenos onde eles ocorrem.

Ainda no domínio da metodologia, utilizamos como instrumento a entrevista semiestruturada, no intuito de conhecer as experiências vivenciadas pelos alunos e professores, ao trabalharem a disciplina História, e a maneira como os conteúdos trabalhados possibilitam, ou não, uma valorização da cultura quilombola e, consequentemente, a preservação dessa identidade.

\section{METODOLOGIA}

Esta pesquisa cujo tema é "Diagnóstico das Dificuldades do Ensino de História no que Tange á Identidade Quilombola em Presidente Kennedy-Es" é uma pesquisa qualitativa que segue um percurso metodológico de trabalho científico. A pesquisa foi desenvolvida nas escolas localizadas nas comunidades quilombolas de Presidente Kennedy, nas quais são atendidos alunos da educação infantil até o quinto ano do fundamental. A Resolução $\mathrm{n}^{\circ} 8$, de 20 de novembro de 2012, estabelece, no art. $8^{\circ}$, que:

Os princípios da Educação Escolar Quilombola deverão ser garantidos por meio das seguintes ações: I - construção de escolas públicas em territórios quilombolas, por parte do poder público, sem prejuízo da ação de ONG e outras instituições comunitárias; 
II - adequação da estrutura física das escolas ao contexto quilombola, considerando aspectos ambientais, econômicos e sócio educacionais de cada quilombo;

III - garantia de condições de acessibilidade nas escolas;

IV - presença preferencial de professores e gestores quilombolas nas escolas quilombolas e nas escolas que recebem estudantes oriundos de territórios quilombolas.

VII - implementação de um currículo escolar aberto, flexível e de caráter interdisciplinar, elaborado de modo a articular o conhecimento escolar e os conhecimentos construídos pelas comunidades quilombolas;

A obrigatoriedade do ensino da história e cultura africana e afro-brasileira nas escolas do país abre um precedente importante para o aprendizado quilombola, assim como as vivências e fazeres dos remanescentes de quilombos contemporâneos devem ser respeitados como um saber essencial para o desenvolvimento de uma nova estrutura de educação no Brasil - essencial para que o país se reconheça como afrodescendente em sua concepção humana e cultural. Assim, as escolas atendem os alunos das comunidades quilombolas, sendo apenas 5\% dos alunos de outras comunidades.

Concordamos com Santos e Candeloro (2006, p. 71), que salientam:

A pesquisa de natureza qualitativa é aquela que permite que o acadêmico levante dados subjetivos, bem como outros níveis de consciência da população estudada, a partir de depoimentos dos entrevistados, ou seja, informações pertinentes ao universo a ser investigado, que leve em conta a idéia de processo, de visão sistêmica, de significações e de contexto cultural. Note-se que a pesquisa qualitativa não tem a pretensão de mensurar variáveis, mas de analisar, qualitativamente, de modo indutivo, todas as informações levantadas pelo acadêmico através da aplicação de um instrumento de coleta de dados adequado. Os mais usais, no plano qualitativo, são a entrevista semiestruturada, o estudo de caso e os grupos focais.

Junto a Ludcke e André (1986, p. 18) em que a pesquisa qualitativa é

[...] aquela que se desenvolve numa situação natural, é rica em dados descritivos e tem um plano aberto e flexível e focaliza a realidade de forma complexa contextualizada. Responde a questões muito particulares e, sendo assim, se preocupa com um nível de realidade que não pode ser quantificado, ou seja, explora um universo de significações, motivos, crenças e atitudes que relacionam-se [sic] a um espaço mais íntimo de relações.

Com a delimitação do tema, foi necessário proceder a uma pesquisa bibliográfica. Como afirma VERGARA (2005, p. 47-48): “A pesquisa bibliográfica é o estado sistematizado desenvolvido com base em material publicado em livros, revistas, jornais e redes eletrônicas, isto é, material acessível ao público em geral”.

De acordo com Minayo (2002, p. 21-22):

[...] a pesquisa qualitativa responde a questões muito particulares. Ela se preocupa, nas ciências sociais, com um nível de realidade que não pode ser quantificado, ou seja, ela trabalha com o universo de significados, motivos, aspirações, crenças, valores e atitudes, o que corresponde a um espaço mais profundo das relações dos processos e dos fenômenos que não podem ser reduzidos à operacionalização de variáveis.

Para contemplar os objetivos propostos, foram utilizadas como instrumento de pesquisa entrevistas semiestruturadas, no intuito de conhecer as experiências vivenciadas pelos alunos e professores, ao trabalharem a disciplina História, e a maneira pela qual os conteúdos trabalhados possibilitam, ou não, uma valorização da cultura quilombola considerando a preservação da identidade.

Concordamos com Gil (2017, p. 25) quando diz: 
As pesquisas podem ser classificadas de diferentes maneiras. Mas para que esta classificação seja coerente, é necessário definir previamente o critério adotado. Com efeito, é possível estabelecer múltiplos sistemas de classificação e defini-las segundo a área de conhecimento, finalidade, o nível de explicação e os métodos adotados.

As entrevistas semiestruturadas foram utilizadas no intuito de atingir os objetivos e permitir aos entrevistados liberdade para falar sobre o tema. Elas foram realizadas nos dias 12 e 14 de fevereiro de 2020.

\section{ANÁLISE E DISCUSSÕES DOS DADOS}

A pesquisa de campo permite conhecer a realidade do objeto de estudo, como também extrair dados, informações, analisar, interpretar fatos e fenômenos, objetivando compreender e explicar o problema pesquisado. Para aprofundar os conhecimentos sobre a educação nas escolas quilombolas de Presidente Kennedy, foi realizada esta pesquisa de campo de natureza qualitativa, que usou como instrumento entrevistas semiestruturadas com professores e alunos das escolas das comunidades quilombolas de Presidente Kennedy. Para descrever o perfil dos entrevistados, foi elaborado o quadro 1, explicativo:

\section{Quadro 1 - Perfil dos professores entrevistados}

\begin{tabular}{|c|c|c|c|c|c|}
\hline Referência & Idade & Sexo & $\begin{array}{l}\text { Local de } \\
\text { moradia }\end{array}$ & Escolaridade & $\begin{array}{l}\text { Tempo de } \\
\text { trabalho no } \\
\text { município }\end{array}$ \\
\hline Entrevistada $\mathrm{n}^{\mathrm{o}} 1$ & 41 & Feminino & $\begin{array}{c}\text { Boa Esperança- } \\
\text {-PK }\end{array}$ & Pós-graduada & 18 anos \\
\hline Entrevistada $\mathrm{n}^{\mathrm{o}} 2$ & 33 & Feminino & $\begin{array}{c}\text { Cacimbinha- } \\
\text {-PK }\end{array}$ & Mestranda & 12 anos \\
\hline Entrevistada n ${ }^{\circ} 3$ & 43 & Feminino & Marataízes & Pós-graduada & 4 anos \\
\hline Entrevistada $\mathrm{n}^{\circ} 4$ & 32 & Feminino & $\begin{array}{l}\text { Cachoeiro de } \\
\text { Itapemirim }\end{array}$ & Superior completo & 1 ano \\
\hline Entrevistada $\mathrm{n}^{\circ} 5$ & 42 & Feminino & $\begin{array}{l}\text { Cachoeiro de } \\
\text { Itapemirim }\end{array}$ & Pós-graduada & 1 ano \\
\hline Entrevistada $n^{\circ} 6$ & 30 & Feminino & $\begin{array}{l}\text { Presidente Ke- } \\
\text { nnedy }\end{array}$ & Pós-graduada & 1 ano \\
\hline
\end{tabular}

Fonte: Elaborado pela pesquisadora, 2020.

O perfil dos professores entrevistados diversifica-se quanto á faixa etária, ao local de moradia, à escolaridade e ao tempo de trabalho no município. Ao entrevistarmos esses professores, tivemos por proposta ter acesso à percepção deles como um todo, desde os que moram nas comunidades até os que moram em outra cidade. $\mathrm{O}$ grau de escolaridade também foi importante, pois foram entrevistados professores recém-formados e professores mestrandos. Contribuíram para os resultados, possibilitando conhecer a realidade das escolas por diferentes olhares, o tempo de experiência e o local de moradia, este muito influencia, porque os professores que moram nas comunidades conhecem um pouco mais sobre as comunidades, em 
virtude de não existirem muitos registros sobre as comunidades quilombolas de Presidente Kennedy, pois os professores de outros lugares têm dificuldades para trabalhar a história das comunidades.

No que diz respeito ao sexo, não houve diversidade, porque a maioria dos professores de ambas as escolas são do sexo feminino. O local de moradia contribuiu muito para o resultado da pesquisa, pois a forma de trabalho para os moradores das comunidades diverge da dos moradores de outras cidades, devido ao conhecimento da história local.

A tarefa de ensinar foi dada às mulheres, mas as funções de domínio público, em sua maioria mais bem remuneradas, atribuíram-se aos homens. Posto isso,

[...] ser professora representava um prolongamento das funções domésticas e instruir e educar crianças, sob o mascaramento da missão e da vocação inerentes às mulheres, significava uma maneira aceitável de sobrevivência, na qual a conotação negativa com o trabalho remunerado feminino esvaía-se [sic] perante a nobreza do magistério (ALMEIDA, 1996, p. 74).

Os questionamentos direcionados aos entrevistados abordavam os seguintes pontos: O que é ser quilombola para você? Você sabia que iria trabalhar em uma comunidade quilombola? Quais os conteúdos curriculares trabalhados na disciplina História que contempla a comunidade quilombola? Geralmente quando são ofertados? A escola possui material didático para somar ao conhecimento dos alunos sobre a comunidade em que estão inseridos? A escola possui projetos que contribuam para o entendimento dos alunos sobre suas raízes? Você repassa valores da comunidade para os seus alunos? De que forma? Você acha que a cultura quilombola está presente nos seus alunos? Como você consegue identificar? Qual a sua opinião sobre preservação da cultura dessa comunidade? O que a escola tem feito para preservar as tradições, costumes e valores dessas comunidades? Na sua opinião, como a escola e o município poderiam contribuir para melhorar a educação quilombola e, consequentemente, preservar a história desse povo?

$\mathrm{O}$ intuito foi conhecer a percepção dos professores em relação ao trabalho desenvolvido pelas escolas das comunidades em estudo e como o aluno era visto do ponto de vista do professor, por isso foram entrevistados professores de diferentes realidades.

A primeira pergunta direcionada foi sobre o que é quilombo, nesta a maioria respondeu palavras de lutas, resistência, não aceitar opressão. Conforme descreveu a Entrevistada n ${ }^{\circ}$ 1: "Para mim é estar dentro de um quilombo, fazer parte da família quilombola, ser parente, neto de pessoas que passaram por dificuldades. É ser resistência" (ENTREVISTADA Nº 1, PESQUISA DE CAMPO, 2020).

Esse conceito é de uma professora nascida e criada na comunidade, de uma família de líderes, que contribuíram e contribuem para a história do quilombo, que o vê como uma família que resiste, até os dias atuais, aos preconceitos e às imposições.

Outra entrevistada respondeu: "Ser quilombola é além do nascimento em um quilombo é se aceita como tal, não nega suas raízes, respeitar seus grios, seus antepassados. É pertencimento" (ENTREVISTADA No 2, PESQUISA DE CAMPO, 2020).

Percebe-se a clareza no conceito de quilombola, demonstrando que a autoafirmação e o sentimento de pertença são necessários, ao fazerem parte de uma comunidade quilombola.

Outra entrevistada respondeu: "Ser Quilombola é um povo especial que passaram por muitas coisas, mas venceram. Ser quilombola são pessoas vencedoras" (ENTREVISTADA No 3, PESQUISA DE CAMPO, 2020). 
Diante das afirmações das entrevistadas, nota-se que o conceito sobre quilombola ainda é esporádico, uma questão antiga que está em pauta desde a década de 1970, porém pouco discutida. Observando que são escolas pequenas em comunidades pequenas, deveria propagar o significado de ser quilombola nas escolas como forma de identidade, uma vez que estão localizadas em comunidades quilombolas.

O conceito de identidade quilombola se dá a partir das representações e interpelações nas quais os sujeitos em questão estão inseridos, e a partir de suas identificações com valores e significados construídos socialmente. O posicionamento coletivo diante desse contexto histórico-cultural ocorre pelo reconhecimento dos sujeitos enquanto grupo, por partilharem histórias, valores e costumes que os remetem a um passado comum e, portanto, a uma identidade compartilhada (FURTADO, 2014, p. 108).

Assim, para entender a cultura quilombola, é necessário vincular ao imaginário social conquistado por seus sujeitos, que se referem a um passado de escravidão, lutas, fugas e constituição de quilombolas.

A segunda pergunta fez referência ao local de trabalho, na qual foi indagado se o professor, no ato da escolha da vaga, sabia que iria trabalhar em uma comunidade quilombola. Dos seis entrevistados, três sabiam que iriam trabalhar em uma comunidade quilombola e três não, demonstrando que, ao escolherem as localidades para trabalhar, poucas informações são disseminadas, pois dos três que declararam que sabiam dois são moradores das comunidades, conforme respondeu a Entrevistada no 5: "Não" (ENTREVISTADA N 5 , PESQUISA DE CAMPO, 2020). A terceira pergunta indagou sobre os conteúdos curriculares trabalhados na disciplina História que contemplam a comunidade quilombola e quando são ofertados. As professoras responderam com base na realidade do município, e uma entrevistada relatou assim:

\footnotetext{
Antes era bem menos trabalhado, os conteúdos não abrangia tanto essa questão de comunidades quilombolas, falava-se em negros, refugiados, mas não se falava do quilombo em si, hoje se trabalha mais em novembro a questão da consciência negra que está dentro dos parâmetros curriculares, dos conteúdos, e também a questão da identidade que se trabalha dentro de diversidade geralmente desde o começo do ano, o que possibilita trabalha a identidade quilombola (ENTREVISTADA $\mathrm{N}^{\circ} 1$, PESQUISA DE CAMPO, 2020).
}

Esse relato mostra que as mudanças nos conteúdos curriculares estão iniciando, no entanto ainda existe uma limitação ao conteúdo que geralmente é trabalhado apenas no mês de novembro, e não no decorrer do ano, uma vez que se trabalha diversidade desde o início do ano, porém com focos abrangentes em que se aproveita o gancho para iniciar a diversidade.

Outra entrevistada respondeu que

[...] os conteúdos trabalhados em história voltados para comunidades quilombolas são referentes à realidade que os escravos passaram, quais foram as pessoas que foram importantes na luta contra a escravidão, esse regime humilhante que foi a escravidão, onde vieram para cá príncipe e princesas, personagens negras importantes para se trabalhar, geralmente trabalhados na semana da consciência negra, porém a indicação da BNCC é que se trabalhe esse conteúdo o ano todo, esse ano iniciou-se na primeira semana de aula ao relatar sobre as belezas da África em relação à natureza e a cultura, usando como literatura o livro 'O marimbondo do quilombo' (ENTREVISTADA No 6, PESQUISA DE CAMPO, 2020).

Esse entrevistado deixou clara a relevância da BNCC em mostrar a necessidade de o professor trabalhar a história afro-brasileira no decorrer do ano, reconhecendo um equívoco que acontece no mês da consciência negra, o que não é o foco da BNCC, e sim a história como um todo.

Um outro entrevistado afirmou "[...] que se trabalha sobre consciência negra em novembro" (ENTREVISTADA No 4, PESQUISA DE CAMPO, 2020). Essa afirmação demonstra que as inquietações ref- 
erentes à BNCC ainda são um pouco desconhecidas por alguns profissionais que não conseguem alinhar os conteúdos curriculares com as exigências da BNCC, com a ressalva de outra entrevistada que questiona a necessidade de incrementar os conteúdos com pesquisas, uma vez que os livros contam a história dos negros no conteúdo sobre a África e muito pouco nos conteúdos sobre o Brasil, mostrando que o material didático disponibilizado no município precisa ser mais bem organizado.

A quarta pergunta questionou se o material didático ofertado pela escola se soma aos conhecimentos dos alunos sobre comunidade quilombola. A resposta foi unânime, pois todos responderam que falta material didático sobre comunidades quilombolas nas escolas e que as escolas precisam melhorar os acervos didáticos sobre a temática, reconhecendo que, todas as vezes que esse conteúdo entra em pauta, é necessário adaptar o conteúdo à realidade dos alunos. A entrevistada $n^{\circ} 6$ relatou: "A escola ela tem pouco livros né, eu até acho que a escola não tem uma cara de quilombola, ainda precisa muito melhorar em relação a isso, o acervo mínimo de livros referentes a realidade quilombola é algo que precisa melhorar" (ENTREVISTADA No 6, PESQUISA DE CAMPO, 2020.).

O quinto questionamento verificou se a escola possui projetos que contribuam para o entendimento dos alunos sobre suas raízes. Esse questionamento causou inquietação, pois a maioria disse que não tem conhecimento de projetos desenvolvidos sobre a escola. Alguns professores referiram-se ao ano passado, em que o único projeto foi desenvolvido no período da consciência negra, projeto montado para que todos os professores trabalhem sobre negros na Semana da Consciência Negra em um dia de exposição, roda de conversa e apresentações culturais na escola. No entanto, pretendem fazer diferente neste ano: trabalhar com projetos que contribuam para o entendimento dos alunos sobre suas raízes no decorrer do ano, porém ainda não planejaram, conforme relatou a Entrevistada n ${ }^{\circ}$ 6: "Não sei se antes era feito algum projeto, porém esse ano pretendemos fazer" (ENTREVISTADA Nº 6, PESQUISA DE CAMPO, 2020).

A sexta pergunta indagou se o professor repassa valores enraizados na comunidade, como histórias de pessoas que se tornaram referências como exemplo de ética para os seus alunos e, se sim, de que forma ocorreu. Os entrevistados declararam que repassam valores das comunidades para seus alunos, conforme afirmou a Entrevistada $n^{\circ}$ 5: “Trabalhamos a consciência negra, as vestimentas, as danças típicas [...]” (ENTREVISTADA No 5, PESQUISA DE CAMPO, 2020).

Embora com pouca propriedade no que refere aos valores da comunidade, os professores estão tentando repassar valores aos seus alunos com e/ou sem exemplos das comunidades. Os valores estão sem disseminados, chama a atenção, contudo, o exemplo utilizado pela Entrevistada $n^{\circ} 2$, uma história pouco conhecida pelos indivíduos de outras localidades:

\footnotetext{
Sim, tive uma experiência ano passado que tive que para minha aula para contar a história de Manoel João para os alunos, porque eu desconheço homem mais íntegro porque ele, além de ser formador dessas comunidades, ele era muito respeitado pela personalidade dele, pelos valores, não foi à toa que ele herdou todas a terras da comunidade, ele era muito honesto, pesquisei com os mais antigos e eles relataram que Manoel João não ia na venda comprar nada, ele mandava o chapéu dele, então a honestidade era um valor. Entendeu? Dependendo da situação, conto a história de Manoel João alencada a educação contemporânea (ENTREVISTADA Nº 2, PESQUISA DE CAMPO, 2020).
}

No entanto, mesmo que as respostas tenham sido positivas, percebe-se que os valores da comunidade não estão sendo repassados dentro das escolas. O intuito era saber se as tradições, costumes, modo de vida, as histórias dos anciões estavam presentes nas escolas e sendo repassados às presentes gerações. Entende-se 
que alguns educadores estão tentando, mas ainda de forma superficial, pois as histórias, os costumes, as tradições ainda não estão no contexto escolar como um todo, à exceção da alimentação, quando as escolas ofertam alimentos adquiridos da agricultura familiar, o que é reforçado e incentivado por alguns profissionais.

O sétimo questionamento procurou saber se é possível identificar a presença da cultura quilombola nos alunos. A Entrevistada $\mathrm{n}^{\mathrm{o}} 3$ relatou: "Sim, com certeza, já vem de casa, está na raiz deles, podendo ser identificado na cor, e como ainda não conheço a comunidade seria só a cor" (ENTREVISTADA N 3 , PESQUISA DE CAMPO, 2020).

A Entrevistada $n^{\circ} 1$ enfatizou: "Acredito que sim. Sobre a cultura quilombola eles comentam que moram na comunidade quilombola, conversamos sobre a cultura e a dança é o jongo" (ENTREVISTADA $\mathrm{N}^{\circ} 1$, PESQUISA DE CAMPO, 2020).

Embora muitos alunos tenham relatado que moram em uma comunidade quilombola e se autoidentificam como quilombola, é necessário consolidar a importância do conhecimento acerca da construção de uma cultura de um povo que é resistência e atualmente luta por reconhecimento, pela preservação da sua identidade, de sua história, de seus costumes e tradições.

Em reposta ao oitavo questionamento sobre a importância de preservar a cultura dessas comunidades, todos os entrevistados acharam importante, como ressalvou a Entrevistada $n^{\circ}$ 5: "Eu vejo, não me adentrei, mas acho que falta ainda muito a melhorar" (ENTREVISTADA No 5, PESQUISA DE CAMPO, 2020).

Embora os moradores das comunidades se autoafirmem como quilombola, muito ainda precisa ser estreitado entre comunidade e escola, pois, mesmo sendo importante a preservação da cultura, os professores defendem a necessidade de um resgate cultural, apesar de saberem que a cultura não permanece estática, estando em constante desenvolvimento. A cultura das comunidades ainda não adentrou as portas das escolas como forma de preservação e repasse de conhecimento local, segundo afirmou a Entrevistada $\mathrm{n}^{\mathrm{o}} 3$ :

\begin{abstract}
Muito importante, não só das pessoas quilombolas, da região, mas qualquer cultura tem que ser preservada, porque é história, a pessoa sem história não tem identidade, então a identidade é importante para a pessoa não importa de qual cultura seja tem que ser preservada sim, tem que ser passada de geração em geração sim, porque como eu disse no início são pessoas que vejo como vencedoras então é muito importante a criança saber que os antepassados dela sofreram passaram por discriminação e ainda passam mas que são vencedores e isso ela precisa ter dentro dela para ter a autoestima alta, eu sou vencedora sim a história do meu povo é uma história de pessoas vencedoras (ENTREVISTADA $\mathrm{N}^{\circ} 3$, PESQUISA DE CAMPO, 2020).
\end{abstract}

A nona pergunta indagou a contribuição da escola para essa preservação das tradições dessas comunidades. As respostas retornaram para o 20 de novembro, e a maioria dos entrevistados considerou as ações desenvolvidas no 20 de novembro como forma de preservação. No entanto, não existe nenhum projeto específico sobre a temática, embora alguns profissionais tenham conhecimento de que as escolas quilombolas têm uma pedagogia própria e nada foi feito até o momento para melhor contribuir no conhecimento dos alunos, apenas atividades relacionadas ao 20 de novembro. A Entrevistada $n^{\circ} 6$ questionou com pertinência:

A escola né, agente enquanto profissional, professores da escola agente tenta nas atividades da escola contemplar isso, só que eu acho que o município precisa reconhecer e valorizar a comunidade, então pra que isso aconteça é preciso que ocorra um processo de valorização primeiro dentro da comunidade para que do lado de fora as pessoas também possam reconhecer isso, ao meu ver, a escola hoje conta com o trabalho do professor em sala de aula o começo é por aí, mas coisas maiores precisam ser feitas. Eu escrevi um projeto chamado 'conhecendo as raízes' pretendo mostrar para a diretora e pretendo implantar 
na escola a partir de abril (ENTREVISTADA N ${ }^{\circ}$ 6, PESQUISA DE CAMPO, 2020).

Percebe-se que algo ainda precisa ser feito, para que a escola tenha características quilombolas, contribuindo para a preservação e disseminação das tradições quilombolas de geração em geração. A Entrevistada $n^{\circ} 2$ disse:

Sinto falta de apoio do poder público em relação a preservação da cultura dessa comunidade, minha opinião é que as pessoas que moram aqui aquelas pessoas que brigam, que lutam, elas têm muito desejo em preservar a cultura, mas eu sinto que, quando chega no poder público, elas se esbarram (ENTREVISTADA N 2, PESQUISA DE CAMPO, 2020).

Em consonância às repostas a esses questionamentos, repele-se a falta de ações públicas para a preservação da cultura afro-brasileira, no entanto, ao cobrarem do poder público, algumas professoras não se posicionaram como agente. Esperam ações públicas, mas não propõem ações a serem desenvolvidas nas escolas.

A última pergunta indagou sobre a maneira como a escola e o município poderiam contribuir para melhorar a educação quilombola e, consequentemente, preservar a história desse povo. A Entrevistada $n^{\circ} 6$ respondeu:

Ao meu ver, é cobrar projetos e ações iniciando pela caracterização da escola, com características quilombolas como já estamos cobrando que o muro seja pintado com o belo da comunidade, já um impacto para quem chega e as pessoas ao verem já vão se sentir representado, valorizado e após um trabalho intenso com os alunos voltado para a realidade quilombola, a questão da África e a valorização do povo negro, contando com o apoio do município para que essas ações sejam feitas (ENTREVISTADA N ${ }^{\circ} 6$, PESQUISA DE CAMPO, 2020).

As professoras, como a entrevistada supracitada, que não conheciam as escolas relataram a falta de característica física nas escolas, discutindo que o povo guarda suas tradições, mas precisa sentir-se valorizado, e o poder público pode contribuir na valorização dos quilombolas com ações voltadas para as escolas existentes em comunidades quilombolas, concordando também com Gama (2015), ao revelar que o poder público deve proteger o patrimônio cultural brasileiro.

Outra entrevistada relatou que “[...] existe o evento do vinte de novembro, mas que é necessário que o município oferte material e formação para os professores" (ENTREVISTADA N 4, PESQUISA DE CAMPO, 2020).

No decorrer das entrevistas, as professoras declararam que o município desenvolve ações para melhorar a educação durante todo o ano e que todas as escolas são contempladas com essas ações, porém faltam projetos específicos para as comunidades quilombolas, destacando que a escola e o poder público precisam de um olhar especial para as comunidades quilombolas, incentivando os alunos a conhecer sua história e possivelmente valorizá-la. Dos seis entrevistados, quatro relataram que é necessário fazer um trabalho no decorrer do ano que englobe as comunidades quilombolas, e não apenas na semana do dia 20 de novembro.

As condições estruturais das escolas também são citadas, uma vez que faltam nelas ambientes educativos adequados e equipados, como biblioteca, laboratório, quadra de esportes, pois a estrutura como já citada são apenas duas salas de aula e um refeitório, não tendo ambientes para contribuir no trabalho do professor e, consequentemente, melhor aprendizagem para os alunos. Os professores precisam buscar meios didáticos para melhor desenvolver a aprendizagem dos alunos, podem propondo projetos, e pedir apoio do poder público, como também levar a comunidade para dentro da escola, fazendo uma ponte entre os saberes e fazeres das comunidades e o conteúdo proposto pelo currículo. 
Para melhor entender se o trabalho está sendo desenvolvido com os alunos e se ele tem sido somado ao conhecimento dos alunos sobre as comunidades em que estão inseridos, os alunos também foram entrevistados. Para descrever o perfil dos alunos entrevistados, foi elaborado o quadro 2, explicativo.

\section{Quadro 2 - Perfil dos alunos entrevistados}

\begin{tabular}{|c|c|c|c|c|c|}
\hline Referência & Idade & Sexo & Local de moradia & Escolaridade & $\begin{array}{l}\text { Tempo de } \\
\text { moradia na } \\
\text { comunidade }\end{array}$ \\
\hline Entrevistada $\mathrm{n}^{\mathrm{o}} 1$ & 9 & Feminino & Cacimbinha & $4^{\circ}$ ano & Nascida \\
\hline Entrevistada $n^{\circ} 2$ & 9 & Feminino & Boa Esperança & $4^{\circ}$ ano & Nascida \\
\hline Entrevistado $\mathrm{n}^{\mathrm{o}} 3$ & 9 & Masculino & Boa Esperança & $4^{\circ}$ ano & Nascido \\
\hline Entrevistada $n^{\circ} 4$ & 10 & Feminino & Boa Esperança & $4^{\circ}$ ano & Nascida \\
\hline Entrevistado $\mathrm{n}^{\circ} 5$ & 9 & Masculino & Boa Esperança & $4^{\circ}$ ano & Nascido \\
\hline Entrevistado $\mathrm{n}^{\circ} 6$ & 9 & Masculino & Cacimbinha & $4^{\circ}$ ano & 4 anos \\
\hline Entrevistado $\mathrm{n}^{\mathrm{o}} 7$ & 12 & Masculino & Cacimbinha & $5^{\circ}$ ano & 2 anos \\
\hline Entrevistado $\mathrm{n}^{\circ} 8$ & 10 & Masculino & Cacimbinha & $5^{\circ}$ ano & 3 anos \\
\hline Entrevistada $n^{\circ} 9$ & 6 & Feminino & Cacimbinha & $1^{\circ}$ ano & Nascida \\
\hline Entrevistada $n^{\circ} 10$ & 6 & Feminino & Cacimbinha & $1^{\mathrm{o}}$ ano & Nascida \\
\hline Entrevistado $\mathrm{n}^{\mathrm{o}} 11$ & 7 & Masculino & Cacimbinha & $2^{\circ}$ ano & Nascido \\
\hline Entrevistado $\mathrm{n}^{\mathrm{o}} 12$ & 7 & Masculino & Cacimbinha & $2^{\circ}$ ano & Nascido \\
\hline Entrevistada $\mathrm{n}^{\circ} 13$ & 7 & Feminino & Boa Esperança & $2^{\circ}$ ano & Nascida \\
\hline Entrevistado $\mathrm{n}^{\circ} 14$ & 7 & Masculino & Boa Esperança & $2^{\circ}$ ano & Nascido \\
\hline Entrevistado $\mathrm{n}^{\mathrm{o}} 15$ & 7 & Feminino & Boa Esperança & $2^{\circ}$ ano & Nascida \\
\hline Entrevistada $n^{\circ} 16$ & 6 & Masculino & Boa Esperança & $1^{\circ}$ ano & Nascida \\
\hline Entrevistada $\mathrm{n}^{\mathrm{o}} 17$ & 6 & Feminino & Boa Esperança & $1^{\circ}$ ano & Nascida \\
\hline Entrevistada $\mathrm{n}^{\mathrm{o}} 18$ & 6 & Feminino & Boa Esperança & $1^{\circ}$ ano & 4 anos \\
\hline Entrevistada $\mathrm{n}^{\circ} 19$ & 6 & Feminino & Boa Esperança & $1^{\mathrm{o}}$ ano & Nascida \\
\hline Entrevistada $n^{\circ} 20$ & 6 & Feminino & Boa Esperança & $1^{\circ}$ ano & Nascida \\
\hline
\end{tabular}

Fonte: Elaborado pela pesquisadora, 2020. 
O perfil dos alunos entrevistados diversifica-se quanto á faixa etária. O local de moradia dos entrevistados é uma das duas comunidades quilombolas em estudo. A escolaridade e o tempo de moradia no município também contribuíram para a pesquisa, pois alguns entrevistados moram há pouco tempo nas comunidades, o que permitiu uma visão de alguém que chegou e já tinha conceitos preestabelecidos, mesmo sendo filhos de pessoas nascidas nas comunidades. Entrevistamos alunos de 6 anos a 12 anos de idade, contemplando desde $\mathrm{o} 1^{\mathrm{o}}$ ano ao $5^{\mathrm{o}}$ ano fundamental $\mathrm{I}$, adequando as formas de fazer à entrevista para melhor entendimento dos alunos e possibilitando abranger a percepção dos alunos como um todo, desde os que nasceram nas comunidades até os que moraram em outra cidade e atualmente são moradores das comunidades.

No que diz respeito ao sexo, foram entrevistados alunos do sexo masculino e feminino, e o local de moradia foi fundamental para o resultado da pesquisa, pois o objetivo era entrevistar alunos moradores das comunidades quilombolas de Presidente Kennedy.

Os questionamentos direcionados aos alunos entrevistados abordavam sobre os seguintes pontos: $\mathrm{O}$ que é ser quilombola para você? Você é quilombola? Por quê? Quem te explicou o que é comunidade quilombola? Seus familiares the contam histórias antigas sobre a comunidade? Quais? Você participa de algum projeto na sua escola? Na sua comunidade, existe algum evento cultural? É importante conhecer a história da sua comunidade? Por quê? De que maneira o conhecimento sobre a comunidade quilombola é trabalhado em sala de aula? Em quais disciplinas ocorrem esses ensinamentos sobre o que é ser quilombola? O que a escola tem feito para preservar as tradições, costumes e valores dessas comunidades?

O intuito foi conhecer a percepção dos alunos em relação ao trabalho ofertado pelas escolas das comunidades em estudo e a maneira como o aluno se posiciona em relação à comunidade em que mora, como ele se autoidentifica e recebe um ensino que se soma ao conhecimento de sua origem.

O primeiro questionamento foi o propósito do que é ser quilombola. Dos 20 entrevistados, 13 relataram que não sabe o que é ser quilombola e sete disseram que sabem, dos quais apenas três deram uma definição para quilombola, conforme relatou a Entrevistada n 1: "É ser da raça negra e morar em Cacimbinha ou Boa Esperança" (ENTREVISTADA N 1, PESQUISA DE CAMPO, 2020), demonstrando que tem conhecimento sobre a afirmação feita. Ser quilombola também é autorreconhecer-se como tal e, ao afirmar que é ser da raça negra e morar em uma comunidade, essa entrevistada reconhece que é parte de um quilombo devido às suas características e ao quilombo de que faz parte.

O segundo questionamento indagou sobre a auto identificação, quando foi perguntado se o aluno era quilombola, e, se a resposta fosse afirmativa, explicar-se-ia o motivo de se considerar quilombola. Dos entrevistados, 15 responderam que sim, dois não souberam e três disseram não. Sendo possível identificar que, apenas com seis anos, mesmo conhecendo pouco sobre a história local, as crianças já se auto intitulam quilombola, conforme afirmou o Entrevistado $n^{\circ}$ 6: “[...] sou porque nasci da raça negra [...]”, como também a Entrevistada $n^{\circ} 20$ : “Sim porque nasci aqui”" (ENTREVISTADOS Nº 6 e 20, PESQUISA DE CAMPO, 2020).

Os entrevistados, em sua maioria, autointitulam-se como quilombola. Esse autorreconhecimento é fundamental, percebendo que, embora as escolas ainda precisem melhorar em suas características físicas, o autorreconhecimento está presente nos alunos.

O terceiro questionamento indagou sobre quem explicou o que é comunidade quilombola. Dos entrevistados, nove responderam que foi a professora, seis responderam ninguém, quatro não souberam e um disse que foi a mãe. Percebe-se que existe um trabalho feito nas escolas que ainda não se tornou referência para um número de alunos. 
A quarta pergunta indagou se os familiares contam histórias antigas sobre a comunidade. Nove alunos relataram que sim, como afirmou a Entrevistada n 2: "Sim, que aqui morava os escravos" (ENTREVISTADA N² 2, PESQUISA DE CAMPO, 2020).

Percebe-se que a história das comunidades está presente em alguns lares como lembranças que devem ser compartilhadas. Onze entrevistados alegaram que não se fala sobre o passado. Falar sobre o passado histórico é de suma importância, pois impede que se percam as lembranças que não foram biografadas, cuja trajetória histórica foi sinônimo de luta e resistência para sobreviver, característica que tem se perdido ao longo dos anos. Dessa forma, repassar aos filhos o que se aprendeu com os pais é fundamental.

A quinta questão indagou sobre os projetos escolares com a temática quilombola. Dos 20 entrevistados, 17 alegaram não participar de projetos na escola, três alegaram participação, dos quais alguns informaram que são apresentações de consciência negra, consolidando as afirmações dos professores de que geralmente essa temática é trabalhada em novembro, conforme afirmou a Entrevistada $n^{\circ}$ 15: “[...] sim consciência negra" (ENTREVISTADA Nº 15, PESQUISA DE CAMPO, 2020).

As escolas deveriam trabalhar com projetos que tratam da história das comunidades, como também do incentivo às tradições culturais. Apenas trabalhar uma semana de aula voltada a produções para a consciência negra não é suficiente para que esse aluno aprenda sobre suas raízes e tradições. Assim, preservar e conhecer a própria história é fundamental para que esse aluno entenda o meio em que está inserido.

A sexta questão indagou sobre a existência de evento cultural na comunidade. Treze disseram que sim, seis negaram e um não soube informar. A Entrevistada n’ 2 afirmou: "Sim. Eventos quilombolas, com apresentação de jongo" (ENTREVISTADA No 2, PESQUISA DE CAMPO, 2020).

Considerando que há seis anos acontece uma festa na comunidade em reflexão ao 20 de novembro, como também encontros de comunidades quilombolas, é importante que as crianças participem desses eventos, e a cultura quilombola até o momento não está fazendo parte das atividades escolares, porque, quando se referiram aos eventos, os alunos não citaram nada que ocorresse na escola, mostrando que ainda existe um superficialidade no trabalho dos professores em relação à organização de eventos culturais.

A sétima perguntou se é importante conhecer a história da sua comunidade: 16 afirmaram que é importante, três não e um não soube responder. Percebemos que muitos apresentaram curiosidades e viram a necessidade de um aprimoramento, conforme afirmou a Entrevistada n ${ }^{\circ}$ : "Sim pra saber mais" (ENTREVISTADA Nº 4, PESQUISA DE CAMPO, 2020).

Conhecer a própria historia é importante, não existe um povo sem história, porque é a história que permite entender a atualidade. Até os alunos entenderam que é importante conhecer a história das comunidades.

A oitava pergunta indagou sobre a maneira como o conhecimento da comunidade quilombola é trabalhado em sala de aula. Dos 20 entrevistados, 11 alegaram não saber que trabalha ou não e nove responderam que fazem conversas, rodas de conversas, explicações ou vídeos. A Entrevistada $n^{\circ} 20$ explanou que "[...] a professora conversou, contou histórias, mostrou fotos e brincou com brincadeiras antigas e da África” (ENTREVISTADA No 20, PESQUISA DE CAMPO, 2020).

Percebemos que alguns professores tentam fazer um bom trabalho apesar das limitações encontradas no ambiente escolar. Entretanto, o tempo que os professores das escolas pesquisadas reservam para essa temática ainda não é o ideal, uma vez que a história local e a afro-brasileira são de ensino obrigatório como expõe a BNCC. Os professores precisam aprofundar o ensino sobre história e cultura afro-brasileira, principalmente porque é um ensino obrigatório com base na Lei no 10.639 . 
A nona pergunta indagou sobre as disciplinas em que ocorrem esses ensinamentos sobre o que é ser quilombola. Onze relataram não saber, quatro disseram em Português, três em História e dois em Matemática. Ao considerar a História como uma ciência que estuda a vida do homem através do tempo, investigando o que os homens fizeram, pensaram e sentiram, entende-se que o conhecimento histórico ajuda na compreensão do homem enquanto ser que constrói seu tempo. Com as respostas dos alunos, foi perceptível que a disciplina História é pouco mencionada, demonstrando um desconhecimento sobre a disciplina que deveria abordar esse estudo.

A última pergunta questionou as ações da escola para a preservação das tradições, costumes e valores comunitários. Dezesseis relataram não saber ou que não fazem e quatro disseram que fazem eventos, conforme afirmou a Entrevistada $n^{\circ} 1$ : “[...] organizam eventos com comidas típicas e apresentações" (ENTREVISTADA Nº 1, PESQUISA DE CAMPO, 2020).

Com base na resposta dos alunos, as escolas não desenvolvem ações para preservar as tradições, costumes e valores das comunidades, o que explica a falta de características físicas nas escolas. A escola deveria desenvolver projetos que contribuíssem para a preservação da história dessas comunidades, uma vez que ficou comprovado que os alunos se autorreconhecem e as comunidades foram reconhecidas pela fundação palmares.

A pesquisa de campo permitiu entender a necessidade de discutir propostas de melhorias para a educação das comunidades, em busca de direcionamentos e apoio didático para melhor desempenho de aprendizagem sobra a história local, considerando que a cultura está em constante desenvolvimento. Porém, a história é importante para humanidade, porque, através dela e dos aspectos socioculturais, se consegue entender a atualidade. As comunidades se auto reconhecem como exposto no segundo questionamento, porém ainda existem algumas mazelas a serem vencidas quando se trata de educação para as comunidades quilombolas, considerando que a educação é um instrumento que forma cidadãos com visão de preservar a identidade e fortalecer as tradições da cultura que são pertencentes, levando em conta que a LDB (Lei ${ }^{\circ}$ 10.639/03) torna obrigatório o ensino da história e cultura afro-brasileira.

Concluímos que é indispensável unir ações em prol da educação histórica das comunidades quilombolas de Presidente Kennedy, buscando formar cidadãos autônomos que conheçam e preservem sua história. Nesse intuito, percebe-se que o município oferta uma educação igualitária para todos os munícipes, as escolas localizadas dentro das comunidades quilombolas precisam trabalhar com mais intensidade a história e cultura afro-brasileira no ensino fundamental com ênfase na história local. Assim, como produto final, propomos um seminário (APÊNDICE C) com o objetivo de melhor preparar os professores que atendem alunos quilombolas, para trabalhar a história local e a cultura e história afro-brasileiras.

O seminário justifica-se pela necessidade de os alunos entenderem a história na qual estão inseridos. Para isso, os professores precisam ser mais bem preparados, para que busquem caminhos para trabalhar a disciplina História, contemplando o aluno como um todo e objetivando contribuir na discussão dos conteúdos expostos e na melhor aprendizagem dos alunos das comunidades quilombolas sobre as suas raízes, a fim de proporcionar um ambiente de trocas de conhecimentos para um ensino que possibilite ao aluno conscientização do porquê de ser quilombola, levantando questões que contribuam no empoderamento dos alunos. 


\section{CONSIDERAÇÕES FINAIS}

As comunidades quilombolas remetem a um espaço marcado por resistências e lutas, caracterizado pelo seu contexto social, cultural e político, carregando marcas de um passado cruel que não pode ser esquecido. O sentimento de pertença deve estar presente nos moradores remanescentes de quilombo, permitindo aos sujeitos que conheçam a história e cultura de seu povo, com liberdade de manter vivos as tradições e costumes de seus ancestrais.

As comunidades estudadas contam com duas escolas que ofertam educação infantil (pré) e ensino fundamental I, com um corpo total de 39 funcionários (diretores, professores, cuidadores, auxiliares, cozinheiras, serviços gerais e vigilantes) e 95 alunos. A estrutura das escolas é padronizada e a merenda de ótima qualidade.

Este trabalho, no que refere às questões educacionais, privilegiou a Resolução $\mathrm{n}^{\mathrm{o}} 8$, de 20 de novembro de 2012, a Lei 10.639/2003 e a BNCC, considerando suas exigências e obrigatoriedade de ensino, levando em conta que a escola não é a única instituição responsável pela difusão do conhecimento e da formação de consciência, porém tendo em vista a existência da obrigatoriedade em falar da África e história afro-brasileira nas escolas e de trabalhar a história local e respeitando a diversidade social, econômica, cultural e política em que cada indivíduo está inserido.

Percebe-se que a educação nas escolas constituídas em comunidades quilombolas de Presidente Kennedy ocorre sem características do meio em que elas estão inseridas, visto que não existem características próprias nas escolas. Mesmo que o sentimento de pertença esteja presente nos alunos, isso não é suficiente para conhecer a história de um povo - o povo negro faz parte da construção de um país, a qual deve ser disseminada para o conhecimento de todos, principalmente dos herdeiros das mazelas da escravidão.

Considerando este contexto, o estudo teve por problema a seguinte questão: Quais experiências são evidenciadas pelos alunos das escolas quilombolas para que eles tenham noção de pertencimento a uma comunidade remanescente? Como resposta, obteve-se que as experiências escolares ainda são minoritárias na soma da noção de pertencimento dos alunos. Conforme relatam alguns professores, há falta de material didático, conhecimento dos profissionais educadores e cobrança no currículo escolar que geralmente se fale sobre comunidade quilombola na consciência negra, o que deveria ser uma data de reflexão visível. Os alunos se afirmam quilombolas devido à noção de pertencimento passada pelos familiares e às afirmações diárias das comunidades que moram, apesar de faltar aprendizagem sobre o porquê desse pertencimento.

Enquanto o objetivo geral pretendeu diagnosticar o ensino disponibilizado aos alunos nas comunidades quilombolas de Presidente Kennedy-ES, verificando se ele possibilita aos escolares ter a noção de pertencimento como remanescentes de comunidade quilombola, os objetivos específicos visaram: situar o que é comunidade quilombola, como também a escravidão no Espírito Santo; verificar como os professores trabalham com os conteúdos da disciplina História na busca da valorização da história local; buscar formas que contribuam para os alunos preservarem a história de suas comunidades; verificar quais conteúdos são trabalhados na escola, de forma que contemplem a preservação da cultura quilombola. Esses objetivos foram atingidos com supremacia, pois possibilitaram responder ao problema e sugerir a proposta de intervenção.

Assim, sugere-se um seminário para somar ao conhecimento dos professores das comunidades, a cobrança do setor responsável que se trabalhe os conteúdos que diz respeito a história afro-brasileira e local 
com mais intensidade, no intuito de fortalecer o conhecimento das tradições e cultura quilombola, levando para dentro da escola as características das comunidades, os somadores da história local e cabendo ao poder público abrir caminhos para a construção de um acervo local para melhor desempenho no trabalho dos professores munícipes ou não. Considerando que ainda faltam material didático e caminhos para direcionar os trabalhos do professor, propõe-se a realização de seminários, por meio dos quais se montem oficinas para o direcionamento do trabalho do professor, o que vai se somar ao conhecimento e à noção de pertencimento dos alunos que, em sua maioria, já se autointitulam como quilombolas.

Concluímos que, em uma sociedade ativa em transformação histórica e cultural, que ocorre com o passar dos anos, a necessidade das pessoas, cercada, em parte, por diversas injustiças históricas, como o caso dos quilombos, exige a demanda constante por entender o contexto e manter as tradições e batalhas por direitos individuais e coletivos. 


\section{REFERÊNCIAS BIBLIOGRÁFICAS}

ALMEIDA, J. S. Mulheres na escola: algumas reflexões sobre o magistério feminino. Cadernos de Pesquisa, São Paulo, n. 96, fev. 1996. p. 71-78.

ARRUTI, J. M. A. A emergência dos "remanescentes": notas para o diálogo entre indígenas e quilombolas. Mana, Rio de Janeiro, v. 3, n. 2, 1997. p. 7-38.

BRASIL. Base comum nacional. Disponível em: $<$ http://basenacionalcomum.mec.gov.br/wp-ontent/uploads/2018/11/7._Orienta\%C3\%A7\%C3\%B5es_aos_Conselhos.pdf $>$. Acesso em: 17 nov. 2019.

BRASIL. Lei $\mathrm{n}^{\circ} 10.639$, de 9 de janeiro de 2003. Altera a Lei ${ }^{\circ}$ 9.394, de 20 de dezembro de 1996, que estabelece as Diretrizes e Bases da Educação Nacional, para incluir no currículo oficial da Rede de Ensino a obrigatoriedade da temática "História e Cultura Afro-Brasileira", e dá outras providências. Diário Oficial [da] União, 10 jan. 2003. Brasília, 2003.

BRASIL. Ministério da Cultura. Fundação Palmares. Disponível em: www.palmares.gov.br. Acesso em: 13 out. 2019.

BRASIL. Ministério da Educação. Diretrizes curriculares nacionais para a educação das relações étnico-raciais e para o ensino de história e cultura afro-brasileira e africana. Brasília: 2004.

BRASIL. Ministério da Educação. Secretaria de Educação Básica. Secretaria de Educação Continuada, Alfabetização, Diversidade e Inclusão. Diretrizes Curriculares Nacionais Gerais da Educação Básica. Brasília: MEC; SEB; DICEI, 2013.

BRASIL. PARÂMETROS CURRICULARES NACIONAIS. Ministério da Educação e do Deporto: Secretaria da Educação Fundamental; Brasília, 1997.

BRASIL. Programa Brasil Quilombola promove a cidadania das comunidades. Disponível em: $\quad<$ https://www.mdh.gov.br/todas-as-noticias/2018/julho/programa-brasil-quilombola-promove-a-cidadania-das-comunidades-no-brasil>. Acesso em: 17 nov. 2019.

BRASIL. Programa Brasil Quilombola: diagnósticos de ações realizadas. Brasília: Secretaria de Políticas de Promoção de Igualdade Racial, 2012.

FURTADO, M. B.; SUCUPIRA, R. L.; ALVES, C. B. Cultura, identidade e subjetividade quilombola: uma leitura a partir da psicologia cultural. Universidade de Brasília, UNB. Brasília-DF. 2014.

GAMA, A. M. O Direito de Propriedade das Terras Ocupadas pelas Comunidades Descendentes de Quilombos. Procurador Federal em exercício na Fundação Cultural Palmares, Brasília. 2015.

GIL, A. C. Como elaborar Projetos de Pesquisa. 6. ed. São Paulo: Atlas, 2017.

LE GOFF, J. História e memória. Campinas: UNICAMP, 1994.

LUDKE, M.; ANDRÉ, M. E. D. A. A pesquisa em educação: abordagens qualitativas. São Paulo: Atlas, 1986. 
MINAYO, M. C. de S. (Org.). Pesquisa social: teoria, método e criatividade. Petrópolis: Vozes, 2002 .

MOVIMENTO NEGRO UNIFICADO. Estatuto do movimento negro unificado. Disponível em: <https://mnu.org.br/quem-somos/>. Acesso em: 17 nov. 2019.

SANTOS, V.; CANDELORO, R. J. Trabalhos acadêmicos: uma orientação para a pesquisa e normas técnicas. Porto Alegre: Age, 2006.

VERGARA, S. C. Métodos de pesquisa em administração. São Paulo: Atlas, 2005. 